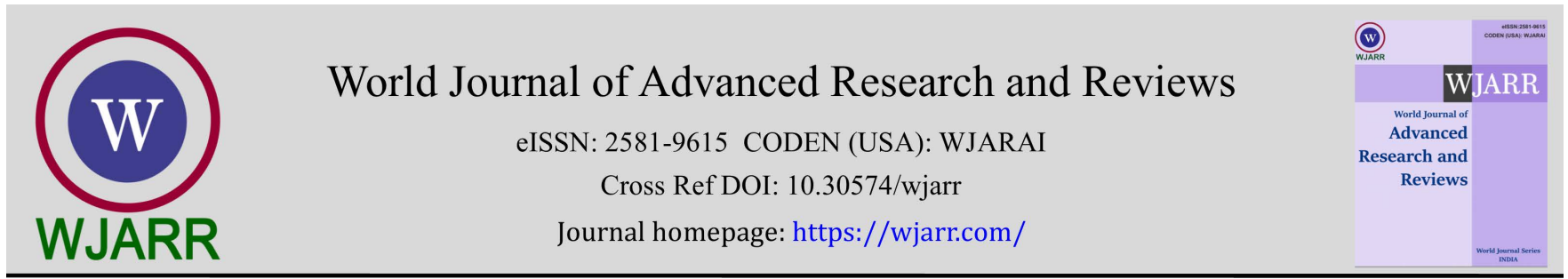

(RESEARCH ARTICLE)

Check for updates

\title{
Multidisciplinary management of orthodontic patients at the University of Port Harcourt Teaching Hospital, Rivers State, Nigeria
}

\author{
Elfleda Angelina Aikins ${ }^{1, *}$ and Chinyere Ututu ${ }^{2}$ \\ ${ }^{1}$ Department of Child Dental Health, Faculty of Dentistry, College of Health Sciences, University of Port Harcourt, Port \\ Harcourt, Rivers State, Nigeria. \\ 2 Department of Child Dental Health, University of Port Harcourt Teaching Hospital, Port Harcourt, Rivers State, Nigeria.
}

World Journal of Advanced Research and Reviews, 2022, 13(01), 513-519

Publication history: Received on 13 December 2021; revised on 17 January 2022; accepted on 19 January 2022

Article DOI: https://doi.org/10.30574/wjarr.2022.13.1.0061

\begin{abstract}
Background: Orthodontic patients may present with complex dentofacial problems that require treatment by more than one dental specialist as well as medical specialists. Such patients present not only with malocclusion but also dental caries, periodontal diseases, dental trauma, missing teeth, sleep apnoea among others. Multi-disciplinary management allows for effective and efficient comprehensive care. The aim of this study was to highlight the multidisciplinary care of orthodontic patients at University of Port Harcourt Teaching Hospital.
\end{abstract}

Materials and Methods: A 7-year retrospective study of patients who attended the Orthodontic Clinic in the Department of Child Dental Health, University of Port Harcourt Teaching Hospital, Port Harcourt, Nigeria. Data collected from the patients' files was analysed using IBM Statistical Package for Social Sciences (SPSS) Statistics for Windows version 25.0 .

Results: A total of 200 patients with an age range of 4-44years comprising 80 (40\%) males and 120 (60\%) females were included in the study. The majority of patients, $145(72.5 \%)$ had scaling and polishing performed by paediatric dentists whilst $53(26.5 \%)$ adult patients were seen by a periodontologist. Eight (4\%) had root canal therapy, composite and glass ionomer cement (GIC) restorations placement by a restorative dentist whilst 6 (3\%) had teeth replaced by the prosthodontist. The patients were also co-managed by oral and maxillofacial surgeons $(28,14 \%)$, Ear Nose and Throat surgeons $(3,1.5 \%)$, paediatricians $(5,2.5 \%)$ and neurosurgeons $(2,1 \%)$.

Conclusion: Multidisciplinary management of our patients was by both medical and dental specialists particularly paediatric dentists and periodontists.

Keywords: Multidisciplinary management; Orthodontic patients; UPTH; Nigeria

\section{Introduction}

The face is regarded as the emblem of beauty, wisdom and emotions as well as standard for acceptance by society and even selection of a partner. Dentofacial aesthetics is a vital tool in evaluating the individuality of a person [1]. The oral cavity in particular is the seat of verbal and non-verbal communication and therefore, a centre of attention [2]. With increasing awareness and emphasis placed on both dental and facial aesthetics the demand for orthodontic treatment as well as functional rehabilitation of occlusion is also on the increase [1,2]. The goal of contemporary dentistry is to maintain the natural dentition in an optimal condition in terms of health, comfort, function, aesthetics and stability [2,3].

\footnotetext{
${ }^{*}$ Corresponding author: Elfleda Angelina Aikins

Department of Child Dental Health, Faculty of Dentistry,College of Health Sciences, University of Port Harcourt, Choba, Port Harcourt, Rivers State, Nigeria.
}

Copyright (C) 2022 Author(s) retain the copyright of this article. This article is published under the terms of the Creative Commons Attribution Liscense 4.0. 
Collaboration among dental specialists particularly in orthodontics has become a common practice [4]. Dental practice is gradually moving from just the general dentist or a single specialist treating a patient to a more multidisciplinary approach [3]. This method allows for dialogue and agreement on the best modes of patient care with the use of the skills and expertise of different specialists. Thus enabling the patient to have access to one stop comprehensive treatment that is efficient and effective at a relatively reduced cost [3,5]. Orthodontic patients may present with complex and multiple dentofacial problems that require treatment by more than one dental specialist as well as medical specialists. Such patients present not only with malocclusion but also dental caries, various periodontal diseases or abnormalities, fractured teeth, missing teeth, peg-shaped laterals, cleft lip and palate, temporomandibular disorders, sleep apnoea as well as a combination of the aforementioned problems [2]. These problems as well as the need for smile makeovers are some of the conditions that are often treated with a multidisciplinary approach [3]. Collaboration among dental and medical specialists needs to be encouraged and well organized in order to achieve the best treatment results [3,5]. This is particularly important in adult patients [6].

The aim of this study was to highlight the multidisciplinary care received by orthodontic patients at our tertiary institution.

\section{Material and methods}

Ethical approval was applied for and obtained from the Research and Ethics Committee of the hospital prior to commencement of this retrospective study. A total of two hundred patients who attended the outpatient Orthodontic Clinic in the Department of Child Dental Health, University of Port Harcourt Teaching Hospital, Port Harcourt, Nigeria from August 2015 to July 2021 were included in this study.

Sociodemographic data of each patient was collated as well as any collaborating dental/medical speciality as well as treatment received. Patients with incomplete records were excluded from the study. Data was collated on a spread sheet and analysed using IBM Statistical Package for Social Sciences (SPSS) Statistics for Windows version 25.0.(Armonk, NY: IBM Corp).

The results were presented using frequencies, percentages and proportions for categorical variables and means and standard deviations for continuous variables. Chi-square was used to test association between variables. Statistical significance was determined at 95\% confidence interval and at $\mathrm{p} \leq 0.05$.

\section{Results}

A total of 200 patients with a female preponderance comprising $80(40.0 \%)$ males and $120(60.0 \%)$ females with an age range of 4-44years, modal age of 11years $(21,10.5 \%)$ and mean age of $13.8 \pm 7.7$ years were included in the study. One hundred and fifty-seven (78.5\%) of the patients were below 18years, only $2(2.2 \%)$ were above 40 years old.

Table1 shows the age and gender distribution of the study participants.

Table 1 Age and gender distribution of patients

\begin{tabular}{|c|c|c|c|}
\hline $\begin{array}{l}\text { Age } \\
\text { (years) }\end{array}$ & $\begin{array}{l}\text { Male } \\
\text { N (\%) }\end{array}$ & $\begin{array}{l}\text { Female } \\
\text { N (\%) }\end{array}$ & $\begin{array}{l}\text { Total } \\
\text { N (\%) }\end{array}$ \\
\hline $0-9$ & $28(35.0)$ & $33(27.5)$ & $61(30.5)$ \\
\hline $10-19$ & $47(58.8)$ & $58(48.3)$ & $105(52.5)$ \\
\hline $20-29$ & $2(2.5)$ & $20(16.7)$ & $22(11.0)$ \\
\hline $30-39$ & $3(3.8)$ & $7(5.8)$ & $10(5.0)$ \\
\hline $40-49$ & $0(0.0)$ & $2(1.7)$ & $2(1.0)$ \\
\hline Total & $80(100.0)$ & $120(100.0)$ & $200(100.0)$ \\
\hline
\end{tabular}

Table 2 depicts the different specialists that co-managed the patients with the orthodontist. Majority were treated by paediatric dentists $(145,72.5 \%)$, followed by periodontists $(53,26.5 \%)$. Only $2(1.0 \%)$ of the patients were solely managed by the orthodontist. 
Table 2 Specialists that collaborated with the orthodontist

\begin{tabular}{|l|c|c|}
\hline Specialists & $\begin{array}{l}\text { Patients } \\
\text { N }\end{array}$ & $\begin{array}{l}\text { Patients } \\
\text { \% }\end{array}$ \\
\hline Paediatric dentist & 145 & 72.5 \\
\hline Periodontist & 53 & 26.5 \\
\hline Oral and Maxillofacial Surgeon & 28 & 14.0 \\
\hline Restorative Dentist & 8 & 4.0 \\
\hline Prosthodontist & 6 & 3.0 \\
\hline Paediatrician & 5 & 2.5 \\
\hline Ear, Nose and Throat Surgeon & 3 & 1.5 \\
\hline Neurosurgeon & 2 & 1.0 \\
\hline Oral Medicine & 1 & 0.5 \\
\hline
\end{tabular}

*Some patients were seen by multiple specialists.

Table 3 displays the various forms of treatment carried out by the dental and medical specialists.

Table 3 Treatment received by the orthodontic patients

\begin{tabular}{|l|c|}
\hline Treatment & Patients N (\%) \\
\hline Scaling and polishing & $198(99.0)$ \\
\hline Extraction & $75(37.5)$ \\
\hline Composite and GIC restoration & $14(7.0)$ \\
\hline Root Canal Therapy & $6(3.0)$ \\
\hline Apicectomy & $1(0.5)$ \\
\hline Crown conversion & $2(1.0)$ \\
\hline Surgical extraction of odontoma/mesiodens & $2(1.0)$ \\
\hline Surgical exposure of impacted teeth & $2(1.0)$ \\
\hline Cyst enucleation & $1(0.5)$ \\
\hline Cleft lip and palate surgery & $2(1.0)$ \\
\hline *Ridge augmentation & $1(0.5)$ \\
\hline *Orthognathic surgery & $2(1.0)$ \\
\hline$*$ Bridge & $2(1.0)$ \\
\hline Halitosis & $1(0.5)$ \\
\hline Removable denture & $1(0.5)$ \\
\hline Medications & $7(3.5)$ \\
\hline$*$ Implant & $3(1.5)$ \\
\hline Adenotonsillectomy & $(1.5)$ \\
\hline Some patients had multiple treatments * Awaiting procedure \\
\hline
\end{tabular}

One hundred and ninety-eight (99.0\%) patients underwent scaling and polishing before the commencement of orthodontic treatment. One hundred and forty-five (73.2\%) of the study participants had scaling and polishing carried out by paediatric dentists while the periodontist treated the remaining 53 (26.8\%) patients. Table 4 
Table 4 Crosstabulation of socio-demographics of the patients with specialists who performed scaling and polishing

\begin{tabular}{|c|c|c|c|c|c|c|c|c|c|c|c|}
\hline \multicolumn{12}{|c|}{ Scaling and polishing age(years) } \\
\hline & \multicolumn{2}{|c|}{$0-9$} & \multicolumn{2}{|c|}{$10-19$} & \multicolumn{2}{|c|}{$20-29$} & \multicolumn{2}{|c|}{ 30-39 } & \multicolumn{2}{|c|}{ 40-49 } & \multirow{2}{*}{$\begin{array}{c}\text { Total } \\
\begin{array}{c}N \\
(\%)\end{array}\end{array}$} \\
\hline & $\begin{array}{c}\text { Male } \\
\text { N (\%) }\end{array}$ & $\begin{array}{c}\text { Female } \\
\text { N (\%) }\end{array}$ & $\begin{array}{c}\text { Male } \\
\text { N (\%) }\end{array}$ & $\begin{array}{c}\text { Female } \\
\text { N (\%) }\end{array}$ & $\begin{array}{c}\text { Male } \\
\text { N (\%) }\end{array}$ & $\begin{array}{c}\text { Female } \\
\text { N (\%) }\end{array}$ & $\begin{array}{c}\text { Male } \\
\text { N (\%) }\end{array}$ & $\begin{array}{c}\text { Female } \\
\text { N (\%) }\end{array}$ & $\begin{array}{c}\text { Male } \\
\text { N (\%) }\end{array}$ & $\begin{array}{c}\text { Female } \\
\text { N (\%) }\end{array}$ & \\
\hline Paedo & $27(100.0)$ & $32(100.0)$ & $38(80.9)$ & $48(82.8)$ & $0(0.0)$ & $0(0.0)$ & $0(0.0)$ & $0(0.0)$ & $0(0.0)$ & $0(0.0)$ & $\begin{array}{c}145 \\
(73.2)\end{array}$ \\
\hline Perio & $0(00.0)$ & $0(00.0)$ & $9(19.1)$ & $10(17.2)$ & $2(100.0)$ & $20(100.0)$ & $3(100.0)$ & $7(100.0)$ & $0(0.0)$ & $2(100.0)$ & $\begin{array}{c}53 \\
(26.8)\end{array}$ \\
\hline Total & $27(100.0)$ & $32(100.0)$ & $47(100.0)$ & $58(100.0)$ & $2(100.0)$ & $20(100.0)$ & $3(100.0)$ & $7(100.0)$ & $0(100.0)$ & $2(100.0)$ & $\begin{array}{c}198 \\
(100.0)\end{array}$ \\
\hline
\end{tabular}

Paedo $=$ Paediatric dentist Perio $=$ Periodontist

Seventy-five (37.5\%) of the patients had tooth extractions. Fifty-seven (76.0\%) of which were performed by paediatric dentists and $18(24.0 \%)$ by oral and maxillofacial surgeons. There was a higher proportion of extractions carried out among female patients than male patients. Majority of the patients that had extraction were within 10-19years (41, $54.7 \%$ ) as seen in Table 5 .

Table 5 Crosstabulation of tooth extractions and specialists with age and gender of study participants

\begin{tabular}{|c|c|c|c|c|c|c|c|c|c|c|c|}
\hline \multicolumn{12}{|c|}{ Tooth extraction age(years) } \\
\hline & \multicolumn{2}{|c|}{$0-9$} & \multicolumn{2}{|c|}{$10-19$} & \multicolumn{2}{|c|}{$20-29$} & \multicolumn{2}{|c|}{ 30-39 } & \multicolumn{2}{|c|}{$40-49$} & \multirow{2}{*}{\begin{tabular}{l}
\multicolumn{2}{r}{ Total } \\
$\mathrm{N}$ \\
(\%)
\end{tabular}} \\
\hline & $\begin{array}{l}\text { Male } \\
\text { N (\%) }\end{array}$ & $\begin{array}{l}\text { Female } \\
\text { N (\%) }\end{array}$ & $\begin{array}{l}\text { Male } \\
\text { N (\%) }\end{array}$ & $\begin{array}{l}\text { Female } \\
\text { N (\%) }\end{array}$ & $\begin{array}{l}\text { Male } \\
\text { N (\%) }\end{array}$ & $\begin{array}{l}\text { Female } \\
\text { N (\%) }\end{array}$ & $\begin{array}{l}\text { Male } \\
\text { N (\%) }\end{array}$ & $\begin{array}{l}\text { Female } \\
\text { N (\%) }\end{array}$ & $\begin{array}{l}\text { Male } \\
\text { N (\%) }\end{array}$ & $\begin{array}{l}\text { Female } \\
\text { N (\%) }\end{array}$ & \\
\hline Paedo & $10(90.9)$ & $9(90.0)$ & $20(95.2)$ & $18(90.0)$ & $0(0.0)$ & $0(0.0)$ & $0(0.0)$ & $0(0.0)$ & $0(0.0)$ & $0(0.0)$ & $57(76.0)$ \\
\hline OMS & $1(9.1)$ & $1(10.0)$ & $1(4.8)$ & $2(10.0)$ & $4(100.0)$ & $5(100.0)$ & $1(100.0)$ & $2(100.0)$ & $0(0.0)$ & $1(100.0)$ & $18(24.0)$ \\
\hline Total & $11(100.0)$ & $10(100.0)$ & $21(100.0)$ & $20(100.0)$ & $4(100.0)$ & $5(100.0)$ & $1(100.0)$ & $2(100.0)$ & $0(100.0)$ & $1(100.0)$ & $75(100.0)$ \\
\hline
\end{tabular}

A total of 28(14.0\%) patients were seen by oral and maxillofacial surgeons as seen in Fig 1 . In all 18 (64.3\%) patients had tooth extractions. Two (7.1\%) patients had an odontoma/mesiodens surgically extracted. Two (7.1\%) had surgical exposure of impacted teeth. Cleft lip and palate surgery was performed in $2(7.1 \%)$ 


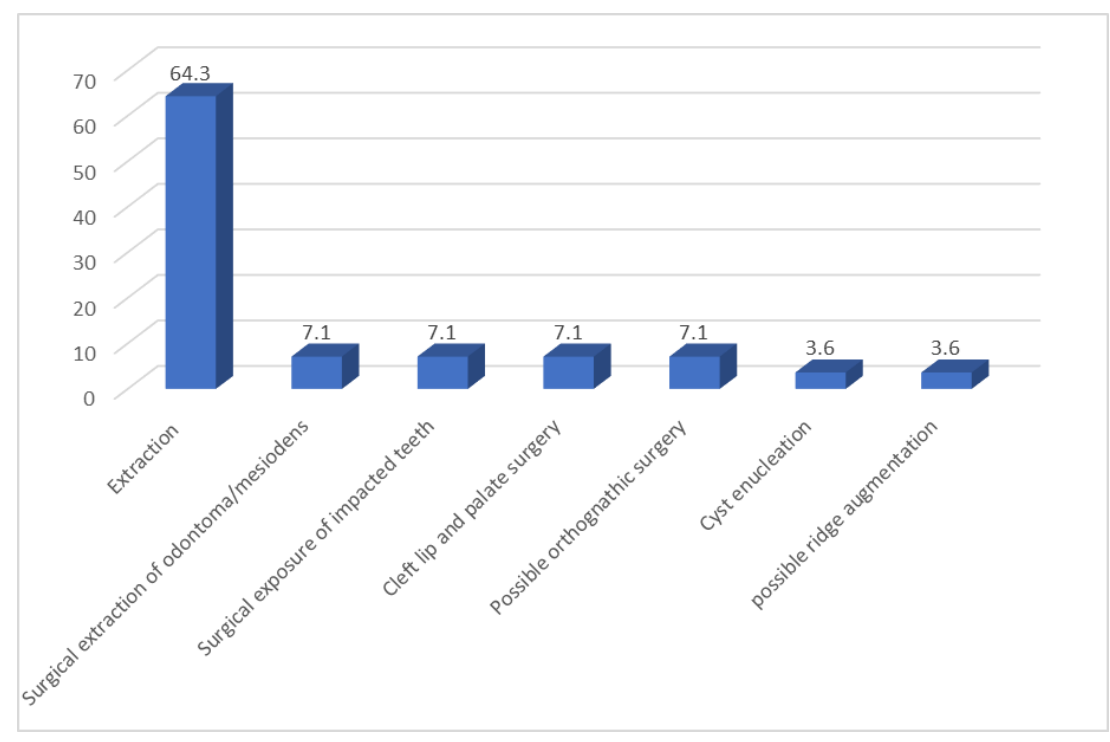

Figure 1 Treatments carried out by oral and maxillofacial surgeons

A total of fourteen $(7.0 \%)$ patients had composite and glass ionomer cement restorations. Majority of these restorations $(10,71.4 \%)$ as well as root canal therapies $(4,66.7 \%)$ were carried out by the paediatric dentist.

Eight (4.0\%) patients were seen by restorative dentist. $4(50.0 \%)$ of these had composite and glass ionomer restorations, $2(25.0 \%)$ root canal therapy with/without apicectomy while the remaining $2(25.0 \%)$ had crown conversion as seen in Fig 2.

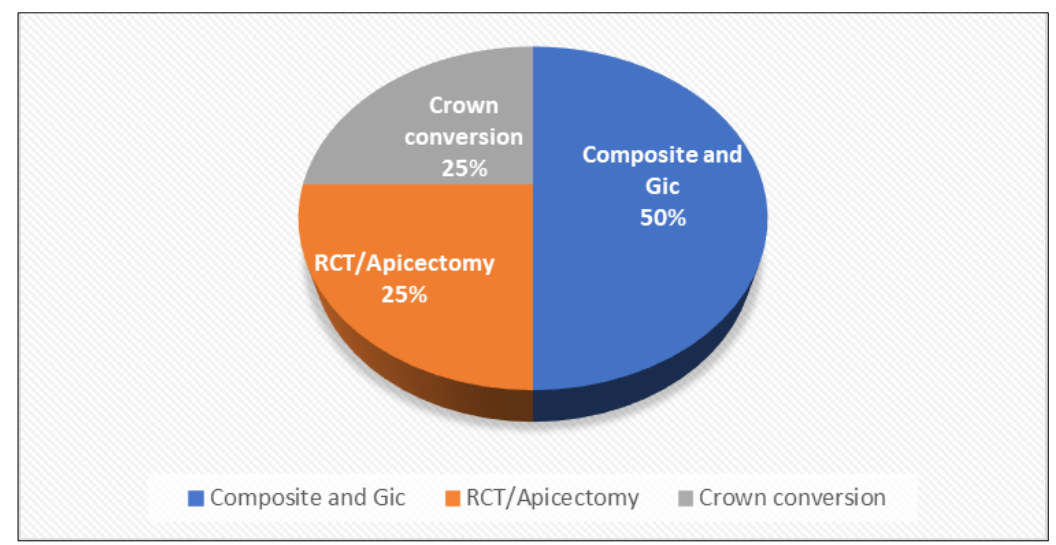

Figure 2 Treatments received from the restorative dentist

Six (3.0\%) patients were seen by the prosthodontist for the replacement of missing teeth.

One (0.5\%) patient was seen by the oral medicine specialist for a complaint of halitosis.

The Ear, nose and throat surgeons (otolaryngologists) treated 3 (1.5\%) patients for adenoid problems and sleep apnoea, whilst $5(2.5 \%)$ participants were managed by paediatricians for the following medical conditions hepatitis, sickle cell anaemia, bronchial asthma, autism, and allergic rhinitis/conjunctivitis. Two $(1.0 \%)$ patients were seen by neurosurgeons due to the presence of a brain tumour and dizziness of intracranial origin.

\section{Discussion}

A multidisciplinary team approach to dental treatment is highly desirable and achievable with the advent of an increased availability of dental and medical specialists in the country. Multi-specialty practices enable patients to access cost effective treatment plans with less stress [5]. The specialty team approach gives a more detailed insight into the patients' problems and enables a holistic approach to management of complex problems [5]. 
In our study majority of collaboration was with the paediatric dentists. This is unlike in some reports in which collaboration was more with oral and maxillofacial surgeons [7] and periodontists [4]. This is because all minor procedures in patients aged 16 years old and below are carried out by the paediatric dentists in our hospital.

Good periodontal health is key for successful orthodontic management, thus collaboration with the periodontist is essential. Each patient in our facility undergoes oral prophylaxis before commencing and after concluding orthodontic treatment, many also require such therapy whilst undergoing treatment. Thus, the ortho-perio collaboration is very important as seen in our study and is comparable to other studies [8]. Among adult patients, collaboration with the periodontist to ensure sound tooth attachment health is also essential [9].

Restorative dentists also play a key role in restoring pleasing smiles to orthodontic patients [10]. Patients with enamel and morphological anomalies such as peg-shaped lateral incisors require such services without which the orthodontist alone cannot give the patient the kind of smile required [11].

As seen in our study sometimes there are incidental findings that may surface during routine investigations. These may be found on radiographs or in laboratory investigations thus the need for collaboration with non-dental specialists like pathologists, Ear Nose and Throat surgeons as well as neurosurgeons.

A few of our patients were reviewed by the otolaryngologists for obstructive sleep apnoea and mouth breathing due to enlarged adenoids. Malocclusion and abnormal mandibular development can have negative effect on respiratory function of a patient. Abnormal mandibular development and positioning can predispose to glossoptosis (posterior displacement of the tongue) which in turn leads to obstructive sleep apnoea. This results in the narrowing of the upper airway thereby predisposing to this condition [12]. Orthodontic treatment in collaboration with the otolaryngologist resolves this $[12,13]$.

Some of our patients were co-managed with paediatricians for medical conditions like sickle cell anaemia, hepatitis, bronchial asthma, autism and allergic rhinitis/conjunctivitis. Sickle cell disease is one of the most prevalent genetic diseases with the greatest preponderance in South-East Asia, Middle East, Mediterranean and Sub-Saharan Africa particularly Nigeria [14]. Patients with sickle cell disease tends to have small faces at all ages which could be attributed to chronic hypoxia leading to haemolytic anaemia. They have hyperdivergent faces, gnathopathy with resultant reduced incisor anchorage and delayed tooth eruption [15]. The management of these patients is therefore interdisciplinary in collaboration with the paediatrician.

Hepatitis B is a transmissible liver infection caused by the Hepatitis B virus and is potentially life threatening [16]. It can lead to chronic liver disease which can result in death due to liver cirrhosis and even hepatic carcinoma. This disease is a major occupational hazard in the dental profession [17]. Children with hepatitis B are managed by paediatricians to reduce the viral load thereby reducing the risk of transmitting it to an unvaccinated orthodontist and also to reduce the complications such as bleeding diathesis that may result.

\section{Conclusion}

Multidisciplinary management of the orthodontic patients was by both medical and dental specialists majorly paediatric dentists, periodontists, Oral and maxillofacial surgeons, paediatricians and ENT surgeons.

\section{Compliance with ethical standards}

\section{Disclosure of conflict of interest}

Dr Elfleda A Aikins and Dr. Chinyere Ututu do not have any conflict of interest.

\section{Statement of ethical approval}

Ethical approval was obtained from the hospital for this retrospective study.

\section{Statement of informed consent}

Informed consent was obtained from all individual participants included in the study. 


\section{References}

[1] Aikins E, Ututu C. Pattern of orthodontic referrals at a Tertiary Hospital in South-South, Nigeria. Nig Health J. 2017; 17(4): 165-173.

[2] Mavreas D, Athanasiou AE. Orthodontics and its interactions with other dental disciplines. Prog Orthod. 2009; 10(1): 72-81.

[3] Patel D, Mehta F, Thakkar S. Role of Team Approach in Orthodontics-Clinical Case Series. J Dent Med Sci. 2012; 3(3): 1-10.

[4] Al-Moghrabi D, Tsichlaki A, Pandis N, Fleming PS. Collaboration in orthodontic clinical trials: prevalence and association with sample size and funding. Prog Orthod. 2018; 19 (1): 16.

[5] Kalia A, Mirdehghan N, Khandekar S, Patil W. Multi-disciplinary approach for enhancing orthodontic estheticscase report. Clin Cosmet Investig Dent. 2015; 7: 83-89.

[6] Sabatoski CV, Bueno RC, Pacheco AAR, Pithon MM, Tanaka OM. Combined Periodontal, Orthodontic, and Prosthetic Treatment in an Adult Patient. Case Rep Dent. 2015;2015:716462.

[7] Peck S. Extractions, retention and stability: the search for orthodontic truth. Eur J Orthod. 2017; 39(2): 109-115.

[8] Rathore N, Desai A, Trehan M, Jharwal V, Puzhankara L, Marya A. Ortho-Perio Inter-relationship. Treatment Challenges. NY State Dent J. 2015; 81(5): 42-7.

[9] Ramachandra CS, Shetty PC, Rege S, Shah C. Ortho-perio integrated approach in periodontally compromised patients. J Indian Soc Periodontol. 2011; 15(4): 414-417.

[10] Lewis BR, Gahan MJ, Hodge TM, Moore D. The orthodontic-restorative interface: 2. compensating for variations in tooth number and shape. Dent Update. 2010; 37(3): 138-148

[11] Kuijpers MA, Loomans B. Combined orthodontic and restorative treatment Ned Tijdschr Tandheelkd. 2015; 122(11): 575-81.

[12] Jackson GW. Orthodontic and Orthognathic Surgical Treatment of a Pediatric OSA Patient. Case Rep Dent. 2016;2016:5473580.

[13] Teixeira AOB, Abi-Ramia LBP, Almeida MAO. Treatment of obstructive sleep apnea with oral appliances. Prog Orthod. 2013; 14: 10.

[14] Adewoyin AS. Management of sickle cell disease: A review for physician education in Nigeria (Sub-Sahara Africa). Anemia. 2015;2015:791498.

[15] Bonan P. Facial features of patients with sickle cell anaemia. Angle Orthod 2011; 81(1): 115-120.

[16] Https: //www.who.int/news-room/fact-sheets/detail/hepatitis-b. Accessed on 17th Dec, 2021.

[17] Dahiya P, Kamal R, Sharma V, Kaur S. "Hepatitis" - Prevention and management in dental practice. J Edu Health Promot. 2015; 4: 33. 